\title{
Clinical Evaluation of Medical Devices: Main Constraints and Specificities
}

\author{
François Parquin ${ }^{1}$, Antoine Audry ${ }^{2}$ and participants of Round Table $N^{\circ} 1$ of Giens XXVII * \\ 1 Foch Hospital, Suresnes, France \\ 2 Medtronic France SAS, Boulogne, France
}

Received March 20 ${ }^{\text {th }}, 2012$; accepted June $4^{\text {th }}, 2012$

\section{Keywords:}

medical device;

clinical evaluation

\begin{abstract}
The purpose of the Giens round table no. 1 was to make proposals and recommendations regarding the clinical evaluation of medical devices.

First, the European and French regulatory rules were examined and compared with the US FDA approach. Thereafter, the main specificities and constraints of the MD sector were underlined and their impact in clinical evaluation described and analyzed. Two areas, cumulating most of these constraints, were consecutively analyzed for concrete case study.

Considering a patient-centered approach, the RT issued eight recommendations directed to manufacturers, physicians and policymakers in order to improve clinical evaluation in the medical device field.
\end{abstract}

Abbreviations: see end of article.

\section{Introduction}

The clinical evaluation of medical devices (MD) covers an extremely wide variety of fields, thereby resulting in the need to make choices in terms of scope and perspective. The work performed at this round table (RT) was therefore deliberately focused on clinical evaluations performed in the interest of the patient, attempting to go beyond the regulatory aspects. It also looked at the subject from the standpoint of acquired experience and expertise rather than that of a review and analysis of existing literature (without totally excluding it however). Finally, the methodological solutions for each of the situations dealt with were deliberately set aside.

Having firstly worked on an inventory of regulations and existing definitions, the group focused on four specificities acknowledged to have a direct impact on the methods of acquiring clinical data, as well as on two sectors, the specific nature of which in terms of clinical evaluation made a valuable contribution to the first level of thematic analysis.

\section{Context}

Two characteristics are likely to significantly affect the production of clinical data and these alone justify the choice of this round table theme:
- the extreme diversity of the world of MD: a simple reading of the regulatory definition of a medical device from the 93/42/CE directive suffices to illustrate this: "A medical device is understood to be any instrument, appliance, equipment, material, product, with the exception of products of human origin, or other article alone or in combination, including the accessories and software involved in its functioning, intended by the manufacturer to be used in humans for medical purposes and whose principal intended action is not obtained by pharmacological or immunological means or by metabolism, but whose function can be assisted by such means",;1]

- there are many types of operator, ranging from health professionals (medical and/or paramedical) to patients themselves and in a variety of environments, including hospitals, doctors' consulting rooms and the patient's home. The MD may be bound to an act that should be evaluated jointly, especially in the case of innovative MD.

\subsection{Regulation procedures and definitions}

The world of MD is impacted by a young, dynamic and constantly developing regulatory environment. This has two main consequences:

- an often partial knowledge of the different stages of the procedure for accessing the market (market release and the reimbursement

* For the list of participants, see end of article. 
Table I. MD procedure in France.

\begin{tabular}{|c|c|c|}
\hline Medical devices & Drugs & Health acts and technologies \\
\hline & Clinical studies & \\
\hline \multirow[t]{2}{*}{ Industry } & Industry & $\begin{array}{l}\text { University Hospitals and health } \\
\text { professionals }\end{array}$ \\
\hline & Market release & \\
\hline $\begin{array}{c}\text { Notified body (CE marking) } \\
\text { ANSM (ex-Afssaps, competent } \\
\text { authority) } \\
\text { Market surveillance }\end{array}$ & $\begin{array}{c}\text { EMA - ANSM (ex-Afssaps) } \\
\text { Evaluation of efficacy and safety } \\
\text { European Commission - ANSM } \\
\text { (ex-Afssaps) } \\
\text { Marketing authorization (MA) }\end{array}$ & \\
\hline \multicolumn{3}{|c|}{ Evaluation of expected benefit/actual benefit } \\
\hline $\begin{array}{c}\text { HAS } \\
\text { CNEDiMTS }\end{array}$ & $\begin{array}{c}\text { HAS } \\
\text { Transparency Commission }\end{array}$ & $\begin{array}{c}\text { HAS } \\
\text { CNEDiMTS }\end{array}$ \\
\hline \multicolumn{3}{|c|}{ Setting of prices/ rates } \\
\hline \multicolumn{2}{|c|}{$\begin{array}{l}\quad \text { CEPS } \\
\text { drugs and devices } \\
\text { after negotiation with } \\
\text { manufacturers }\end{array}$} & $\begin{array}{l}\text { UNCAM } \\
\text { ment rate of drugs } \\
\text { d reimbursement rate of acts } \\
\text { tiation with the representatives } \\
\text { rofessionals }\end{array}$ \\
\hline \multicolumn{3}{|c|}{ Reimbursement decision } \\
\hline \multicolumn{2}{|c|}{$\begin{array}{c}\text { Ministry of Health } \\
\text { Draws up a list of reimbursable drugs and medical devices }\end{array}$} & $\begin{array}{l}\text { UNCAM } \\
\text { Draws up a list of } \\
\text { reimbursable acts }\end{array}$ \\
\hline
\end{tabular}

ANSM : (french) National Agency of Drug Safety and Health Products (ex-Afssaps [french Food Safety Agency of Health Products]); CEPS : (french) Economic Committee of Health Products; CNEDIMTS: National Committee for the Evaluation of Medical Devices and Health Technologies; EMA : European Medicines Agency; HAS: Haute autorité de santé (French National Authority for Health); MA: marketing authorization; MD: medical devices; UNCAM : national union of insurance founds.

procedure), even though they play a key role in the development of clinical proof. This section details the main determinants, with their analysis proving to be very formative in the subsequent RT discussion;

- a fast-changing pace: changes emerge even before we have had the time to measure the impact of the previous changes. The content of this article must therefore be reviewed in the light of any changes introduced in the system.

\subsubsection{In France}

There are two main, consecutive stages (table I). Anticipation of the specific requirements at each of these two stages may result in some data produced for the first being usable for the second.

Marketing authorization: CE marking. This is a european marketing authorization procedure, managed by European notified bodies, and accredited by the competent authorities of each EU country. Three directives ${ }^{[2,3,4]}$ form the regulatory basis and set the essential performance and safety requirements to which the MD have to comply in order to be released onto the European market. They are completed by standards and interpretation tools called Meddev, which includes reference frameworks that companies must use as the basis for proving compliance of their MD with the essential requirements.

Broadly speaking, CE marking uses three procedures to demonstrate compliance with the performance and safety requirements defined by these directives, namely risk analysis, pre-clinical evaluation (test benches, tests on animals, etc.) and clinical evaluation. These three elements aim to prove that the risk/benefit ratio of the device is favourable.

These provisions were strengthened in the currently applicable 2007/47/CE directive, ${ }^{[5]}$ which:

- specifies exactly what is covered by the "clinical data" terminology;

- renders the implementation of clinical investigations specific to the MD in question increasingly systematic, with requirements being higher for higher risk categories (implantable MD and class III MD), for which "Clinical investigations shall be performed unless it is duly justified to rely on existing clinical data";

- systematizes post-market surveillance procedures aimed at ensuring the regular updating of clinical evaluation data: "The clinical evaluation and its documentation must be actively updated with data obtained from the post-market surveillance. Where post-market clinical follow-up as part of the post-market surveillance plan for the device is not deemed necessary, this must be duly justified and documented." 
The 2007-47/CE directive thus creates a real paradigm shift by placing clinical investigation at the heart of the risk/benefit demonstration process and as one of the pillars of risk/benefit ratio management. However, as it has only been recently applied, its effects are still difficult to measure.

Obtaining reimbursement. Obtaining reimbursement ${ }^{[6]}$ depends on an independent, scientific evaluation performed by the CNEDiMTS (National Committee for the Evaluation of Medical Devices and Health Technologies), a commission de la Haute Autorité de Santé (French National Authority for Health or HAS).

Basically, a product must have first demonstrated a favourable expected benefit (EB)/actual benefit (AB). It must also demonstrate the level of improvement in the expected benefit (IEB)/actual benefit (IAB) that it provides in relation to therapeutic alternatives/ existing diagnostics.

Analysis of the clinical tests forms the backbone of the proof of $\mathrm{EB} / \mathrm{AB}$ and IEB/IAB. As regards $\mathrm{EB} / \mathrm{AB}$, the interest of the product is assessed in relation to clinical data showing a favourable risk/benefit ratio and the position of the MD in the therapeutic/diagnostic strategy. The notion of IEB/IAB is based on clinical studies evaluating the device in relation to a reference comparator in the therapeutic strategy. If necessary, the CNEDiMTS assesses the associated act, with a similar analysis grid.

In its assessment, the CNEDiMTS specifies the indications, the corresponding target population, any specific conditions of use, the length of registration, the terms for re-registering and whether they depend or not on a post-registration study.

This clinical evaluation process is an ongoing process that is intended to be the subject of regular reassessment. It is based on the production of clinical data both upstream and downstream from reimbursement.

\subsubsection{What about american marketing authorization regulations?}

Established for a longer period than the $\mathrm{CE}$ regulations, the Food and Drug Administration (FDA) that oversees the marketing authorizations of MD is based on principles that are similar to those governing the European framework, namely:

- classification of products according to the risk associated with their use and the definition of processes requiring more demanding (cumulative) proof for higher risk categories;

- two processes, the $510(\mathrm{k})$ and the PMA, with the latter being much more demanding and reserved for high-risk products and/ or those with no real equivalent on the market;

- the strengthening of requirements as regards the demonstration of clinical proof;

- the definition of exemption measures to account for certain, highly specific situations (such as humanitarian devices and substantial equivalence).

The main difference can doubtlessly be summed up by closer consideration of the therapeutic field in question. This results in specific criteria for the classification of MD and numerous specific guidelines. The USA is currently considering and discussing how to change the guidelines, thus compensating for some of the limitations.

\subsection{Clarifications}

At this point, it is interesting to focus on two notions that played a prominent role in the roundtable discussions. The first involves confusion over vocabulary and the second, the principle of equivalence, which is a particularly important issue in the world of MD.

\subsubsection{Vocabulary issues}

This is doubtlessly one of the foremost conclusions of the RT: the number of misunderstandings arising from different interpretations of terms by different players, the most noticeable being the notion of clinical evaluation.

- clinical evaluation: for CE marking, this notion refers to the existence of pertinent clinical data resulting from clinical investigations into the MD or other sources. As regards reimbursement, this refers to the data resulting from clinical tests;

- clinical investigation/clinical tests: studies specifically conducted on the MD in question;

- clinical evidence: the total amount of existing preclinical and clinical data (directly regarding the MD in question or not);

- performance: the effect claimed by the manufacturer;

- destination: "the use for which a medical device is intended according to the indications supplied by the manufacturer in the labelling, instruction leaflet or promotional material", ${ }^{7]}$ for products for therapeutic use, the destination is often specified via the indications.

\subsubsection{The notion of equivalence}

This notion is essential and involves both the CE marking plan ${ }^{[8]}$ and the regulations drawn up by the FDA. ${ }^{[9]}$

It is based on the principle that equivalence can only be claimed if the product does not generate any additional risk AND is used in the indications and conditions strictly identical to the product with which it claims equivalence.

This is why regulations include three different and cumulative aspects to prove such equivalence:

- clinical: MD used in a destination (part of body, etc.) and in similar indications for a similar target population (age, anatomy and physiology) in similar conditions;

- technical: MD presenting similar technical characteristics (materials used, viscosity, resistance, etc.) and design, using, if applicable, similar implementation and/or operative methods;

- biological: MD with similar materials and surface in contact with the human body (body parts, fluids). 
Table II. MD approach according to the degree of innovation.

\section{Degré de nouveauté Degree of novelty}

\begin{tabular}{|c|c|c|c|c|}
\hline \multirow{2}{*}{\begin{tabular}{|c|} 
Degré de \\
nouveauté \\
$\begin{array}{c}\text { Degree of } \\
\text { novelty }\end{array}$ \\
\end{tabular}} & \multirow{2}{*}{$\begin{array}{l}\text { Type de nouveauté } \\
\text { Type of novelty }\end{array}$} & \multicolumn{3}{|c|}{$\begin{array}{l}\text { Nouveauté à dominante } \\
\text { Innovation where the dominant is : }\end{array}$} \\
\hline & & $\begin{array}{l}\text { Technologique } \\
\text { Technological }\end{array}$ & & $\begin{array}{l}\text { Clinique } \\
\text { Clinical }\end{array}$ \\
\hline 5 & $\begin{array}{l}\text { Innovation majeure } \\
\text { Major innovation }\end{array}$ & $\begin{array}{l}\text { Rupture technologique } \\
\text { Breaking technology }\end{array}$ & $\begin{array}{l}\text { et } \\
\text { and }\end{array}$ & $\begin{array}{l}\text { Impact clinique fort } \\
\text { Strong clinical impact }\end{array}$ \\
\hline & $\begin{array}{c}\text { Innovation } \\
\text { (dispositif innovant) } \\
\text { (innovative device) }\end{array}$ & $\begin{array}{l}\text { Rupture technologique } \\
\text { Breaking technology }\end{array}$ & $\begin{array}{l}\text { ou } \\
\text { or }\end{array}$ & $\begin{array}{l}\text { Impact clinique fort } \\
\text { Strong clinical impact }\end{array}$ \\
\hline & $\begin{array}{l}\text { Nouveauté substantielle } \\
\text { Substantial novelty }\end{array}$ & $\begin{array}{l}\text { Incrémentation technique } \\
\text { Incremental technology }\end{array}$ & $\begin{array}{l}\text { et } \\
\text { and }\end{array}$ & $\begin{array}{l}\text { Impact clinique modéré } \\
\text { Moderate clinical impact }\end{array}$ \\
\hline & $\begin{array}{l}\text { Nouveauté modérée } \\
\text { Modarate novelty }\end{array}$ & $\begin{array}{l}\text { Incrémentation technique } \\
\text { Incremental technology }\end{array}$ & $\begin{array}{l}\text { ou } \\
\text { or }\end{array}$ & $\begin{array}{l}\text { Impact clinique modéré } \\
\text { Moderate clinical impact }\end{array}$ \\
\hline & $\begin{array}{l}\text { Nouveauté inexistante ou mineure } \\
\text { Lacking or minor novelty }\end{array}$ & $\begin{array}{l}\text { Technologie connue } \\
\text { Known technology }\end{array}$ & et & $\begin{array}{l}\text { Impact clinique inchangé } \\
\text { Unchanged clinical impact }\end{array}$ \\
\hline
\end{tabular}

MD: medical devices

This notion can apply to a variety of products, including high risk products, such as two single-chamber cardiac pacemakers.

Products do not therefore have to be strictly identical to be equivalent. However, any differences in any of these three aspects must be justified in terms of risk/benefit ratio. This data can be established on test benches, by testing on animals or the production of specific clinical data. On account of these issues, the subject remains highly complex.

\section{The constraints and specificities of MD clinical evaluation}

Firstly, four MD specificities were analyzed independently. Then two particular sectors, considered to be emblematic, were selected, namely implantable MD (IMD) and MD used for compensating for disability.

\subsection{MD specificities}

\subsubsection{Specificity 1: the heterogeneity of the world of MD}

Common sense alone suggests that in the light of the extreme heterogeneity of $\mathrm{MD}$, a single response is impossible and cannot be repeatable. Several different approaches and situations therefore need to be considered:

- predictability of performance: a cane, glove, gauze, dental inlay or an electric syringe must all comply with technical standards that predict their performance. There is therefore normally no point in setting up specific clinical tests. This is only the case, however, if the equivalence criteria are not affected (the claim, clinical environment of use and technical characteristics). When gauze claims to have a supplementary or different action or efficacy, the issue of conducting clinical studies should arise;

- the level of innovation of the MD in question. Is it an incremental development or a breakthrough development with a high clinical impact? In both cases, clinical tests are necessary, but with different and/or adapted objectives required (table II). The specific support measures for breakthrough innovations, whether at the preclinical development stage or at the early clinical phase were not discussed at this roundtable. In other cases, a question arises: is the MD similar to another previously evaluated MD? This apparently simple notion, although made explicit by European (Meddev 2.7.1) or American (510k procedure) is in fact complex and must not be stated, but rather proved. For example, a hyaluronic acid for intra-articular injection to treat arthrosis may appear similar to another, but a variation in the degree of polymerization may result in different effects or a different 
length of action. The CNEDIMTS has therefore deemed it essential that all hyaluronic acids claiming MD status supply clinical studies comparing them to MD or drugs that have already been evaluated. We can also point to the example of implantable cardiac defibrillators. The clinical interest of the primary function, namely delivering an internal electric shock to treat ventricular rhythm disorders, does not need to be proved for each new device of this category; compliance with a series of highly precise and well-defined technical specifications is necessary and sufficient. However, the addition of a new algorithm for delivering the shock or a new function should result in a two-fold demonstration, namely that of its interest in the therapeutic strategy, together with that of the absence of a negative effect on the primary function of the defibrillator. Most of the time, clinical studies will therefore be required. CE marking takes this principle into account, but information leading up to it is not made public, largely for patent reasons. A compromise needs to be found with manufacturers, which could act as a basis for a more complete demonstration aimed at ensuring that the similarity is not accompanied by a difference in clinical performance or side-effects;

- MD categorization. As regards coronary stents, there are international standards and HAS recommendations that specify the type of study required to ensure the correct level of clinical evaluation of a new stent. This approach is not yet frequently used, as few reference frameworks are currently available. They provide indications at a certain moment in time, according to the available scientific knowledge. Indications for bare stents or drug eluting stents have evolved over the last few years. In addition, for a same device, these recommendations only apply for a specific indication. For example, certain stents that were initially developed for the treatment of peripheral arterial vascular disease may also be used for venous diseases or even for biliary diseases. Studies obviously need to be performed once again for each indication.

None of these various approaches can be used alone. They complement each other and evolve, particularly in relation to the development of scientific knowledge on the subject involved.

\subsubsection{Specificity 2: life cycles}

Some classes of MD evolve very rapidly, in an incremental fashion. The main consequence of this lies in the fact that these life cycles may be shorter than the length of the clinical tests. Analysis of a study performed with different versions is sometimes therefore near-impossible and constituting subgroups retroactively cannot be recommended. Even if there are some methodological solutions in existence, it is preferable to avoid such situations by anticipating the appearance of an often foreseeable incremental evolution in the initial plan. An independent scientific committee should be able to take a minor incremental evolution into account in a study. The main point therefore is to distinguish the elements that, in the new generation, may affect the results of the clinical evaluation in progress and take account of this in the statistical analysis. By correctly calculating the number of subjects and centres necessary and by promoting a rapid implementation of studies, this type of situation can be more easily avoided. The use of interim criteria to predict clinical efficacy was also one of the approaches discussed at the RT in order to reduce the gap between life cycles and the length of evaluations.

An incremental implementation leading to a new reference must be the subject of a specific study when it affects the risk/benefit ratio. For example, the anchoring device of an endovascular prosthesis may be modified, potentially lessening the risk of endoleaks, but the risk of haemorrhage when fitting the device must not be increased.

At the other end of the scale, the lifespan of a device can be very long in a patient. Such is the case, for example, with a number of IMD implanted in children or young adults, as well as implantable orthopaedic or hearing prostheses. In this case, long-term monitoring is fundamental and long-term studies must prove continued efficacy.

\subsubsection{Specificity 3: the operator dependent character}

The operator dependent character is a basic and defining element in the use of MD. A hip prosthesis has its own qualities and indications, but experience of the surgeon, the extent of their knowledge of the device, the choice of a suitable approach and implantation area are obviously determining factors to obtain the required efficacy. Likewise, certain side effects are more related to the procedure and the operator then to the MD itself, such as the risk of haemorrhage or infection. In certain cases, the operator may be the patient themselves (such as self-monitoring glycaemia devices for diabetics or vehicles for the disabled), requiring specific technical training.

A natural consequence of this characteristic is the notion of the learning curve. This needs to be taken into account at all stages of the preclinical and clinical development, as well as in the day-today use of the MD once it has been released on the market, by providing, for example:

- a very precise description of the method for fitting or using the device and the development of adapted and often specific ancillaries;

- training in the method, which is a prerequisite for the use of medical devices and an integral part of the risk management plan. Test benches and simulators are increasingly used in this field to help with the acquisition of interventional skills;

- the consideration of feedback to define the initial incremental evolutions, both in the MD itself and in any ancillaries.

Whatever the case, the tests must include this learning curve by scheduling an initial acquisition phase in the number of subjects necessary, for example, and/or by any interim analyses. Studies conducted after market release must also monitor the impact of the 
learning curve on use of the MD and thus identify the environmental conditions that are most suitable for an efficient distribution of the technique.

\subsubsection{Specificity 4: small populations}

This situation is very frequent in the field of MD. For example, the target population of an aerosol therapy system to treat patients with cystic fibrosis totals 4500 patients and that of a microprocessor controlled mono axial knee prosthesis is 1200 to 1400 patients, whilst that of drug-eluting coronary stents is around 65000 patients. This is a long way from the target population of an antihypertensive drug and more often in population levels that come under orphan drugs. This phenomenon is particularly frequent in the field of disability or customized MD. The patients concerned are spread over the whole country and treated by numerous teams of staff, which further reduces the number of team-supervised patients. The notion of a reference centre can rarely be applied in these cases. Solutions - largely methodological - can be proposed, including for example the performance of clinical tests on a European level or the exhaustive listing of treated patients. Systems to facilitate this are currently being developed, particularly on a european level.

\subsection{Two emblematic sectors: implantable $M D$ and $M D$ compensating for disability}

\subsubsection{Sector 1: implantable MD (IMD)}

Evaluation of the risk/benefit ratio over time is at the heart of the problem posed by IMD. In the paediatric field for example, a mechanical valve prosthesis fitted to a young adult will have a very long life span. Robust interim assessment criteria, predicting longterm evolution, are often difficult to determine. Modelling using test benches have a useful role to play, especially for determining the wear of the materials used and their structure. For example, radiological criteria are proposed to predict the wear of hip prostheses and to try to foresee the risk of loosening.

Angiographic criteria have been widely used in an attempt to determine coronary intra-stent restenosis, but it gives little information about the risk of stent thrombosis. For other devices, such as hearing implants, there are "fuzzy" breakdowns, that are not "all or nothing". If the breakdown is gradual, the implanted person becomes accustomed to it, rather like the clogging of a microphone. The penalty for those implanted is a failure in performance, which they put down to their personal capacity. It is therefore necessary to monitor implanted patients throughout their lives. The obsolescence of an MD must also be taken into consideration. Beyond the notion of a guarantee, how can the "after sales service" of an IMD implanted in a child be ensured when technology evolves? Other specific features of IMD must also be taken into account, such as the double blind difficulty, the operator dependent character.

Part of the solution lies in reconciling the two approaches, namely evaluation for market authorization, which is often limited in terms of monitoring or reliance on interim criteria, and the postmarket surveillance, which should prove the continued performance of the MD and its reliability, potentially based on registers representing the monitored population. In France, the practice of registers is not highly developed and would benefit from being encouraged in order to better anticipate and monitor the risk/benefit ratio throughout the life of the MD.

\subsubsection{Sector 2: devices compensating for disability}

This is a vast field that is complex to analyze. MD are very diverse, have highly variable life cycles, are often operator dependent and involve small populations spread over the whole of the country.

However, in order to tackle the subject, it is important to try to fully understand what a disability actually is. Let's begin with a reminder of the definition of a disability, as laid down in the 2005 law for "Equal rights and opportunities": "A disability constitutes any activity limitation or participation restriction to life in society that a person may undergo in her/his environment, due to a significant, lasting or permanent alteration of one or more functions, be it physical, sensory, mental, cognitive or psychological, due to multiple disability or due to a disabling health condition". [10] Article 11 of the same law stipulates that disabled people are entitled to compensation for the consequences of their disability and that this should form the basis of their life plan. Finally, disability should be considered under a number of complementary aspects:

- illness/disorder, deficiency (for example, a disability resulting from impaired hearing);

- incapacity (disabled as regards hearing sound signals);

- participation (disabled if the work includes information transmitted by sound signals).

The ICF (International Classification of Functioning, Disability and Health) is also widely used. Based on a 5-level scale, this quantifies all the components, namely organic functions, anatomic structures, activity, participation and environmental factors. It is also important for determining status of the product in question, whether it is a support product or an MD.

Therefore, evaluation is naturally bipolar as regards MD for disability. It comprises a technical aspect that is subject to compliance with standards and a clinical aspect, which will necessarily be focused on the needs of the disabled person and their life plan. Despite these particularities, clinical studies are possible. Efficacy should be evaluated via improvement in the deficiency, ability to perform and participation. The methodology of the tests should be adapted and the objectives must be clearly identified. In view of the 
reduced size of the target population, it will sometimes be necessary to resort to international multicentre studies that are the only source able to provide rapid answers to the questions that arise. Wider use of global quality of life criteria, or even personalized criteria, is essential.

\section{The final proposals and recommendations of the RT}

\subsection{Clarify the terminology of certain terms, including clinical evaluation, clinical tests and performance}

As the discussion and debate unfolded, it soon became clear that evaluation terminology could have different meanings, depending on if the speaker was referring to texts related to European CE marking or the field of national approach. Once these barriers have been lifted, the discussion can rely on a common basis. This action could be implemented by the bodies in charge of these subjects, through the wide distribution of a glossary specifically intended for MD and their clinical evaluation, which would be valid from whatever perspective.

\subsection{Clinical evaluations must make clear the risk/benefit ratio, the indications, the position in the therapeutic strategy and the target population}

This perspective has the advantage of allowing a synthesis between the requirements of the different stakeholders in the health care system: patients remain the central element, but there are also operators and those responsible for ensuring that public funds are spent wisely and in optimal conditions.

\subsection{Clinical tests are not always appropriate}

The very nature of some medical devices (such as the mechanical or physical aspects) results in their evaluation being more easily modeled on test benches, due to higher predictability of their behaviour in a clinical situation and the slightest variability in their performances from one patient to another. In addition, the incremental development process of MD raises the difficult question of equivalence. Efforts already made both on european and american levels must be continued in order to describe the methods that guarantee the best demonstration level of this equivalence. Furthermore, the results must be more communicated in an effective manner. A high level of confidence could be introduced, being the only factor likely to contribute to recognition of the justification not to resort to clinical tests to prove the risk/benefit ratio of certain MD.

\subsection{CE marking data should be more accessible and transparent in a number of fields, including risk management, equivalence and the drafting of the summary of main characteristics of the device}

The data is still too often confined to the CE marking files and is rarely communicated either to the health authorities (proactively) or, even less frequently, to health professionals (patient-users, health care workers or managers). This has been started in the fields of highly innovative products, under the impetus in particular of the ex-Afssaps (actually ANSM) innovation department and, more recently, programmes managed by the HAS. In this context, exchanges can be introduced far upstream, leading on a local level to wider and better structured communication as regards the different existing evaluation data. It is certain that everyone would benefit from the existence of a summary of MD characteristics that would in particular include the evaluation data, supporting the claims put forward for the MD in the CE marking application.

\subsection{Invest in long-term post-market monitoring, in particular in the fields of IMD}

The role of evaluation in the pre-marketing phase is essential to ensure a sufficient level of expected service both in terms of benefit and the associated risks. It has become apparent that it is equally essential to invest in new tools and methods for post-market monitoring. Initiatives have emerged both on a european level (post-market clinical follow-up) and in France for reimbursement (post-registration studies). It is essential to continue the work in these two areas, developing the most suitable methods and creating a convergence, insofar as possible, to ensure the development of a useful and representative database. Efforts must also be made to allow use of existing databases, such as the ISMP and the National System of Inter-Program Health Insurance Information (SNIIRAM) for MD follow-up.

\subsection{Raise awareness of MD evaluation among users}

Any person faced with the introduction of clinical tests knows how the usual methods (implemented in other fields, such as drugs) must be adapted to take into account the specificities of MD. Solutions exist and should be favoured in order to guarantee the highest level of proof possible for each MD category. Increasing the raising of awareness and training would lead to the creation of a common culture among all the players in the evaluation circuit. It could be managed jointly between field players and the bodies involved, such as the ex-Afssaps (actually ANSM) and the HAS, based on reference documentation available to everyone and an awareness 
program via the existing subsidiaries (CCP, DRCI, OSEO, Competitive clusters, Aviesan, ARIIS, scientific institutions, etc.).

\subsection{Extend the interactions between the CPP /Committee for the Protection of Persons) and the world of MD}

The work jointly carried out with the CPP to give more information about the specificities of MD evaluation needs to be continued and exchanges should be encouraged as regards advances in methodology specifically used in MD evaluation.

\subsection{Adapt and optimize the existing evaluation support programs (STIC, PHRC, etc.)}

These programs have recently been reformed. An assessment would measure the extent to which these changes provide an answer to the objectives specified in the RT.

\section{Acknowledgements}

The authors offer their sincere thanks to all the participants for their involvement and contribution to the work of this roundtable, particularly Anne Josseran for colleges stick support and sound advice.

\section{Participants.}

Antoine Audry (Medtronic France SAS), Bernard Avouac (Laser), Alexandre Barna (AP-HP, CEDIT), Catherine Denis (HAS, CNEDiMTS), Bruno Frachet (AP-HP, Hôpital Avicenne), Isabelle Fontes (Abbott Vascular), Chrystelle Gastaldi (ministère de la Santé, Direction Sécurité sociale), Jean-Claude Ghislain (ANSM, DEDIM), Bernard Guillot (CHU Montpellier), Muriel Granger (Boston Scientific), Anne Grumblat (CHU Besançon), Anne Josseran (SNITEM), Gérard Luzergues (Ceiso), Pierre-Olivier Marguet (Hospices Civils Lyon, DRCI), Noël Martinet (CHU Nancy), Nadine Normand (AFNOR), François Parquin (Hôpital Foch), Rémy Pécault (CNAMTS), Sandrine Pitel (Qualissima), Françoise Roca (3M), Fabrice Romano (Eye Tech Care), Emilie Rufach (GMED), Dominique Thiveaud (Europharmat), Daniel Vasmant (ministère de l'Économie, des Finances et de l'Emploi, DGCIS).

\section{Conflicts of interest. None.}

Abbreviations. AB: actual benefit; ANSM: (french) National Agency of Drug Safety and Health Products (ex-Afssaps [french Food Safety Agency of Health Products]); ARIIS: Alliance for Research and Innovation of the Health Industry; CNEDIMTS: National Committee for the Evaluation of Medical Devices and Health Technologies; CPP: Committee for the Protection of Persons; DRCI : (french) Department of Clinical Research and Innovations; EB: expected benefit; FDA: Food and Drug Admin- istration ; HAS: Haute Autorité de Santé (French National Authority for Health); IAB: improvement in the expected benefit; IEB: improvement of the expected benefit; IMD: implantable medical devices; MD: medical devices; OSEO: (french) public establishment with industrial and commercial purpose; RT: round table; SNIIRAM: National System of Inter-Program Health Insurance Information; STIC: programm to support innovative techniques; PHRC: hospital programm of clinical research.

\section{References}

1. Article L665-3 du Code de la Santé Publique. http://www.legifrance.gouv.fr/affichCodeArticle.do?cidTexte=LEGITEXT000006072665\&idArticle=LEGIARTI000006694037\&dateTexte $=20120311$

2. Directive européenne 90/385/CE (dispositifs médicaux implantables actifs), 1990. http://eur-lex.europa.eu Notice.do?val=161305:cs\&lang=fr\&list=217630:cs,201866:cs,161305:cs,\& pos $=3 \&$ page $=1 \& \mathrm{nbl}=3 \& \mathrm{pgs}=10 \& \mathrm{hwords}=\&$ checktexte $=$ check box\&visu=\#texte

3. Directive européenne 93/42/CE (dispositifs médicaux), 1993. http://eurlex.europa.eu/

Notice.do?val=294514:cs\&lang=fr\&list=335843:cs,329393:cs,329392:cs,31 $7994: c s, 294514: c s, \&$ pos $=5 \&$ page $=1 \& \mathrm{nbl}=5 \&$ pgs $=10 \& \mathrm{hwords}=\&$ checktext $\mathrm{e}=$ checkbox\&visu=\#texte

4. Directive européenne 98/79/CE (dispositifs de diagnostic in vitro), 1998. http://eur-lex.europa.eu/

Notice.do?val=226562:cs\&lang=fr\&list=272230:cs, 236122:cs, 234415:cs, 23 $4414: c s, 226562: c s, \&$ pos $=5 \&$ page $=1 \&$ nbl $=5 \&$ pgs $=10 \&$ hwords $=\&$ checktext e=checkbox\&visu=\#texte

5. Directive européenne 2007/47/CE, 2007. http://eur-lex.europa.eu/ Notice.do?val=455903:cs\&lang=fr\&list $=491391: c s, 459453: c s, 459452: c s, 45$ 5903:cs, \&pos $=4 \&$ page $=1 \& \mathrm{nbl}=4 \&$ pgs $=10 \&$ hwords $=\&$ checktexte $=$ check box\&visu=\#texte

6. Parcours du dispositif médical - Guide HAS, 2009. http://www.hassante.fr/portail/upload/docs/application/pdf/2009-12/ presentation_guide_dm.pdf

7. Art R5211-4, http://www.legifrance.gouv.fr

8. Meddev 2.7.1, 2009. http://ec.europa.eu/health/medical-devices/files/ meddev/2_7_1rev_3_en.pdf

9. FDA guidance: substantial equivalence to a US marketed predicate device. http://www.fda.gov/medicaldevices/deviceregulationandguidance/howtomarketyourdevice/premarketsubmissions/premarketnotification510k/ default.htm

10. Article L.114 du code de l'action sociale et des familles, loi pour l'égalité des droits et des chances, la participation et la citoyenneté des personnes handicapées. 11 février 2005. http://www.legifrance.gouv.fr/affichCodeArticle.do?cidTexte=LEGITEXT000006074069\&idArticle=LEGIARTI000006796 446\&dateTexte $=20111028$

Correspondence and offprints: François Parquin, Respiratory Intensive Care Unit, Foch Hospital, BP 36, 92151 Suresnes Cedex, France.

Email: f.parquin@hopital-foch.org 